\title{
SPATIAL DISTRIBUTION OF THYROID CANCER IN ROMANIA
}

\author{
DOI: http://dx.doi.org/10.18509/GBP.2020.43
}

UDC: 303.71:616-006.6-051(498)

\author{
Iulia Daniela Nedelcu ${ }^{1,2}$ \\ Corina Silvia Pop ${ }^{3}$ \\ Marin Burcea ${ }^{4}$ \\ Adrian Gabriel Simion ${ }^{1,2}$ \\ Daniel Peptenatu ${ }^{1,2}$ \\ ${ }^{1}$ University of Bucharest - Faculty of Geography, Bucharest, Romania. \\ ${ }^{2}$ Research Centre for Integrated Analysis and Territorial Management, Bucharest, Romania. \\ ${ }^{3}$ University of Medicine and Pharmacy "Carol Davila", Bucharest, Romania. \\ ${ }^{4}$ University of Bucharest -Faculty of Administration and Business, Bucharest, Romania.
}

\begin{abstract}
According to the United Nations, cancer is a topic of public interest, being the second cause of illness and mortality of the population everywhere. Thyroid cancer (according to international classification, C73-C75 - malignant tumors of the thyroid and other endocrine glands), is a category with a high degree of spatial concentration, the investigation of the spatial dimension of the distribution is an essential condition in understanding the patterns of manifestation of the determinants. This study is based on data on oncology prevalence and mortality provided by the Ministry of Health, organized at the level of cancer type according to the distribution at the territorial administrative unit level. Spatial analyzes and spatial distribution were made for 2008-2017 for prevalence and 2008-2016 for mortality. Depending on this database, GIS and statistical methods and techniques are applied. The results obtained show the concentration of cases in well-defined geographic areas, which require multidisciplinary research to determine the causes that determine the development of thyroid cancer.
\end{abstract}

Keywords: oncology, prevalence, mortality, spatial dimension, GIS.

\section{INTRODUCTION}

Thyroid cancer is a distinct category of tumors with relatively low values, compared to the other categories, responsible for $1 \%$ of all cancerous disorders and being the most common type of cancer in the category of malignant tumors of the thyroid and other endocrine glands C73-C75 [1], with increasing values over the last two decades [2]. The incidence of thyroid cancer has increased by a few percent globally over the past 20 years, in the United States, for example, the rate of thyroid cancer has increased from 4.3 per 100,000 populations in 1980 to 12.9 per 100,000 populations in 2008 ; the same thing happens in the case of oncological mortality, the values are increasing [3]. From the specialty literature we find that the determinants of this category of cancer have not been precisely identified, the main categories of determinants being environmental factors, genetic factors and demographic factors. Thyroid cancer is more common in the female population, and the average age is 45-50 years [1]. Environmental factors influence the disease of the endocrine glands, more precisely the exposure to ionizing radiations [3]. The reaction of radiation exposure differs from person to person, the aspects that are followed refer to the person's age at the time of exposure, his medical history, and body 
mass index. When we talk about the geographical distribution of diseases, geography has a special role in understanding life and medical science. This topic is increasingly debated, and as the method of representing medical data, increasingly used in recent years, the main reason would be the significant increase in the volume and availability of data, as well as awareness of the role that the geographical environment plays in influencing health. [4], [5], [6], [7]. Most authors analyze this data strictly from a statistical point of view, but the main way of representing data is spatial modeling, as geographic information systems can produce sets of maps in an automated manner and can perform different types of spatial analyzes [8]. Geographic Information Systems is one of the tools used by the public health field, capable of collecting, storing and manipulating statistical data with spatial reference [9], [10], [11], [12]. The tool is used to carry out strategies for developing and maintaining public health through surveillance, risk assessment, disease analysis and prevention. At the same time, spatial models can be made to precisely locate the affected area and to allocate resources efficiently [13], [14]. The development of the Geographic Information Systems and their correlation with the medical data helped to develop strategies for the development and maintenance of public health through surveillance, risk assessment, analysis and prevention of diseases [15], being represented in the form of spatial models.

\section{RESEARCH METHODOLOGY}

\section{Study Area}

To carry out this work, we used a national medical database for all the 3181 territorial administrative units that Romania has (Figure 1). The database used is reported for a period of 10 years, starting with 2008, immediately after Romania's accession to the European Union (2007). Why 2008? Because before Romania's accession to the European Union, the medical data did not exist in a unitary system, they differed from one institution to another, and after accession, all these data were centralized and updated by trained personnel.

\section{Statistical data used}

The medical database used in this article was initially represented in the form of medical records, and later transformed into a national coverage database represented at the level of the 3181 territorial administrative units for both the number of registered cases (prevalence). between 2008-2017, as well as for the number of deaths due to one or more types of cancer (oncological mortality) for a period of 9 years between 2008-2016. The medical database is divided according to the international classification on 3 levels, but for this paper we have been summarized in category C73 - C75 - Malignant tumors of the thyroid and other endocrine glands, total, female and male.

\section{Spatial modeling of thyroid cancer (C73 - C75) in Romania}

For the graphic component was used the mentioned medical database with national coverage, provided by the Ministry of Health regarding category C73 - C75 - Malignant tumors of the thyroid and other endocrine glands (level 3), total, female and male. The spatial models were realized by taking a few simple steps, starting from the processing of the initial medical records using a relational database system RDBMS-Postgres SQL, thus generating the database used in this material, a database that allows multiple records. The processing, aggregation and pivoting time is highly dependent on the hardware 
configuration used. Following these steps, the data is exported in an Excel-compatible table format, for later use in spatial modeling programs.

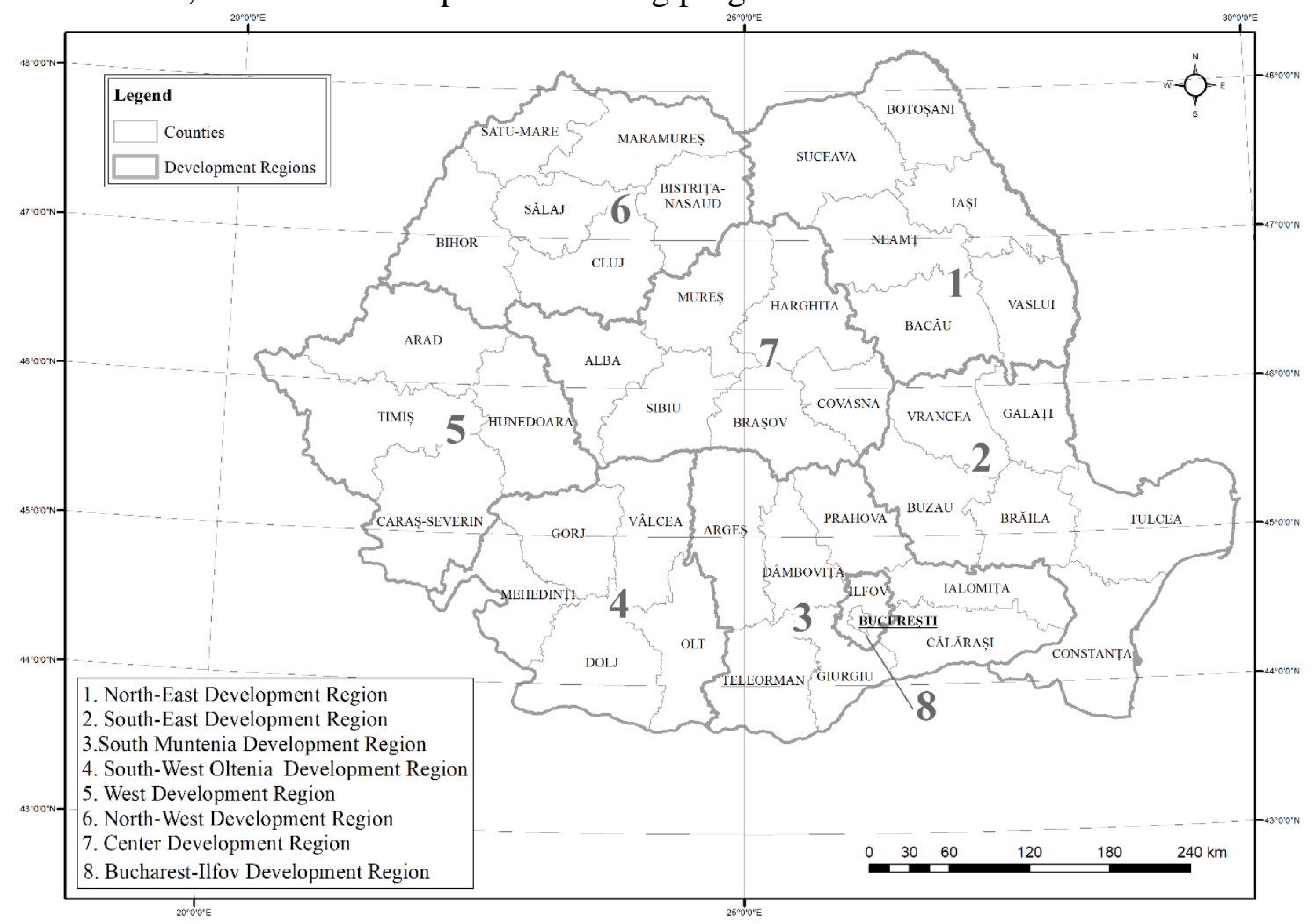

Figure 1. Development regions and counties of Romania.

Finally, the spatial models are realized with the help of a GIS software, respectively QuantumGIS, by connecting to the database on cancer incidence, assigning to each territorial administrative unit the registered values. The data are classified into 5 ranges of values expressed in absolute values and represented cartographically in gray tones, high values with open tones, towards white, and small values with dark tones, towards black. Thus, the prevalence of thyroid cancer was represented according to the total number of cases, the number of cases female population and male population in the form of 30 cartographic materials specific to the period 2008-2017.

\section{RESULTS}

Geographical distribution of prevalence Malignant tumors of the thyroid and other endocrine glands (C73 - C75), total, female and male.

Analyzing the 3 images (Figure 2, Figure 3 and Figure 4) regarding the geographical distribution of total cases of malignancies of the thyroid or other endocrine glands (code C73-C75), for the total population, female and male, we observe a series of localities in which the recorded values exceed the last established interval for the whole period analyzed 2008-2017, as well as localities in which there are no registered cases.

In figures 2 which represents the absolute number of cases, the localities in which the registered values exceed 10 cases for the whole period analyzed are: Bucharest Sector 1 with 36 cases registered in 2012 and 12 in 2017; Cluj Napoca, Cluj county with a maximum number of cases registered in 2010, 36 cases and 13 cases in 2017. 


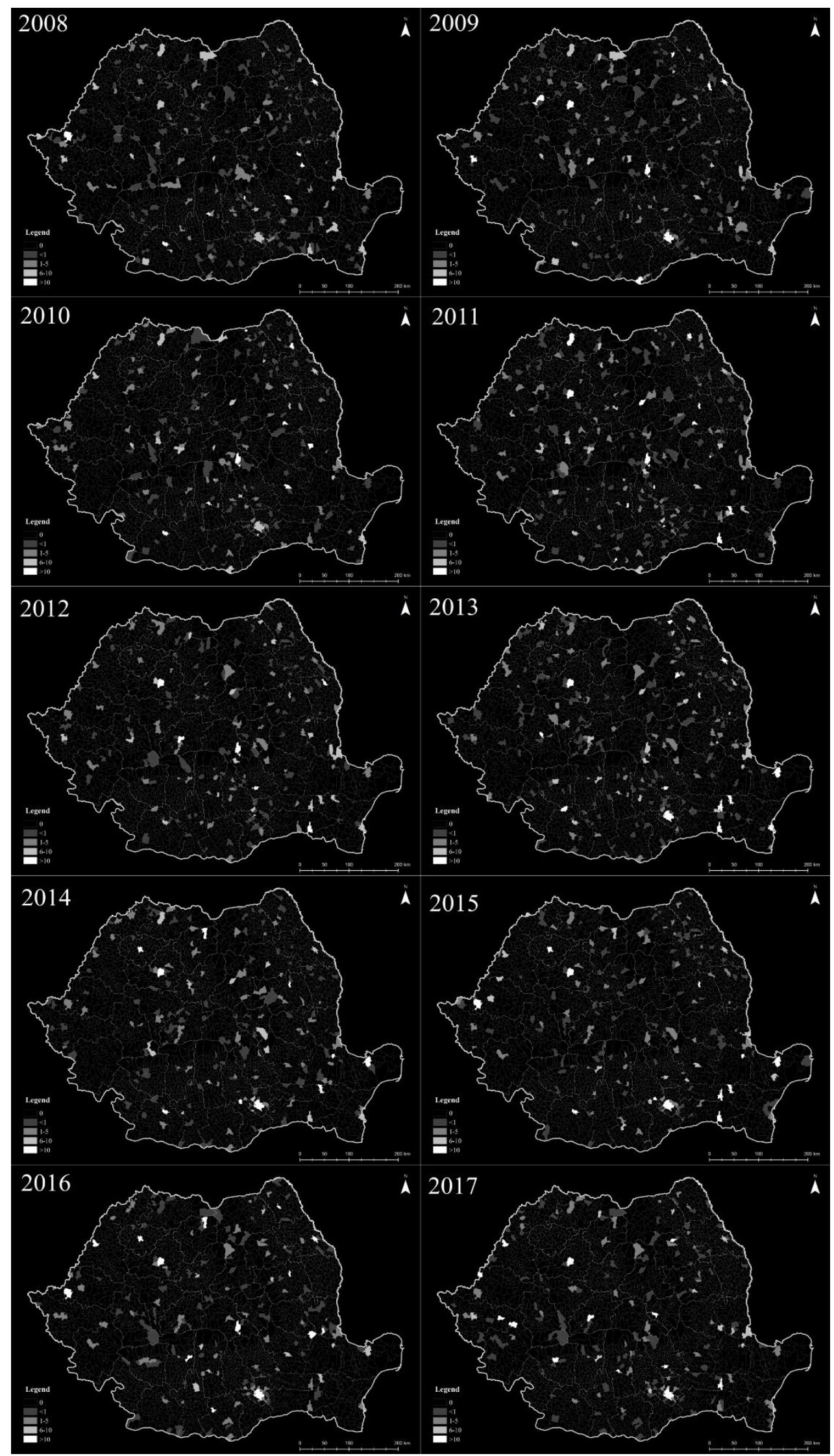

Figure 2. Geographical distribution of prevalence Malignant tumors of the thyroid and other endocrine glands (C73 - C75), total. Source: Ministry of Health 


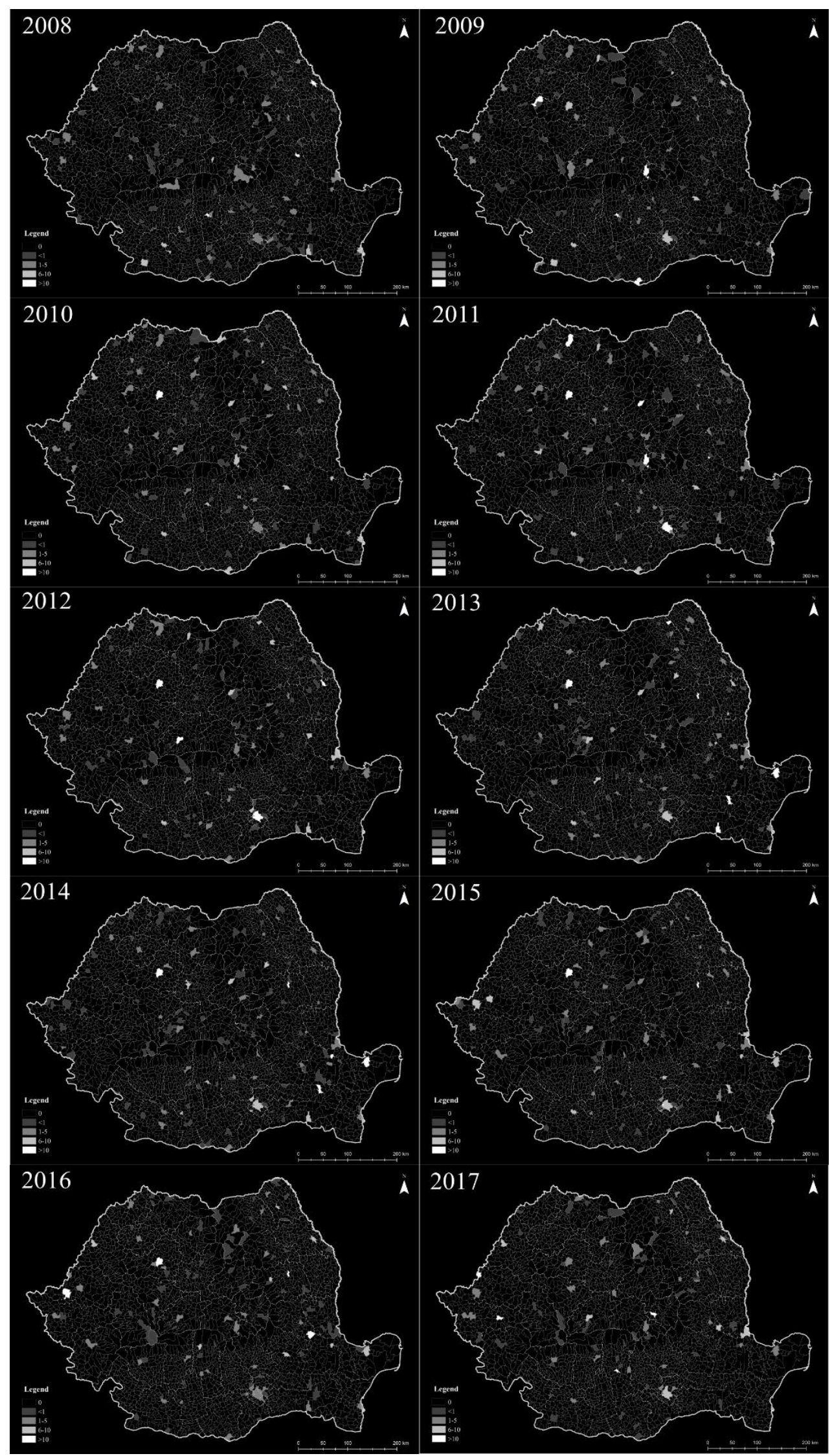

Figure 3. Geographical distribution of prevalence Malignant tumors of the thyroid and other endocrine glands (C73 - C75), female. Source: Ministry of Health 


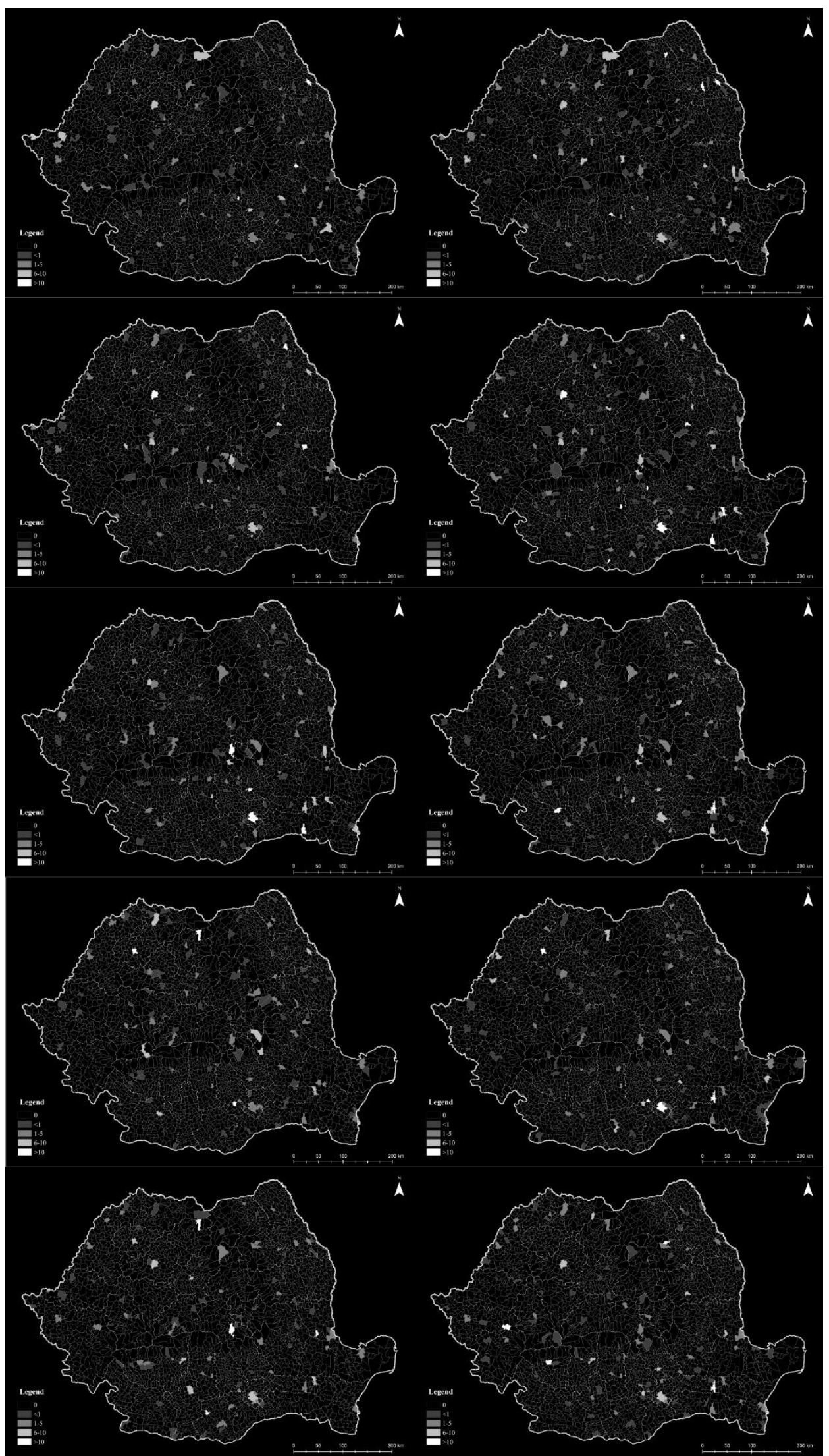

Figure 4. Geographical distribution of prevalence Malignant tumors of the thyroid and other endocrine glands (C73 - C75), male. Source: Ministry of Health 
Other localities with high values recorded in one or more years from the analyzed period are: Bucharest, Sector 5 with 17 cases in 2008, reaching 13 cases in 2017; Bucharest Sector 2, with 15 cases in 2008 and 8 cases in 2017; Calaraşi county Calarasi recorded 8 cases of thyroid cancer in 2008, 23 cases in 2013, decreasing to 2 cases in 2017; in Brasov, Brasov County were registered 21 cases in 2011, reaching 5 cases in 2017. A number of localities recorded a single isolated case of thyroid cancer in a single year and the rest of the period was not reported either one case: Bârsana (Maramureș county) with a single case registered in 2017; Sacalaseni locality (Maramureș county) with a case of thyroid cancer registered in 2015; the town of Balauseni from Mures county recorded a single case of thyroid cancer in 2009.

Figure 3 shows the situation of the geographical distribution of thyroid cancer for the female population. Of the localities where values were registered over the last threshold, in one or more years of the analyzed period, we mention: Pitesti (Argeș county) where there were 16 cases of thyroid cancer in 2008, reaching 18 cases in the year 2017; Bucharest, sector 3 with 11 cases in 2008 and 7 in 2017; Bucharest, sector 6 with 12 cases in 2013, reaching 4 cases in 2017; Sfântul Gheorghe locality in Covasna county, where 19 cases were registered in 2017, and in 2008 a single case. Among the localities with minimum or non-existent values we mention the following localities such as: Dudu locality (Ilfov county) with a single case in 2013; Jilava locality (Ilfov county) with a single case registered in 2009; Terchești (Vrancea county) with a case registered in 2009, etc.

Figure 4 shows the situation of the male population regarding the geographical distribution of thyroid cancer for the period 2008-2017. The localities in which values were recorded belonging to the last established threshold, in one or more years are: Bucharest, sector 3 with 18 cases in 2012 and 5 cases in 2017; Bucharest, sector 1 with 13 cases in 2011 and 6 cases in 2017; Nadrag locality (Timiș county) where 0 cases were registered in 2008 and 21 cases of thyroid cancer in 2017. Regarding the situation of the localities with minimum or non-existent values we mention localities such as: Dobroești (Ilfov county) with 1 case in in 2011, in the rest of the period no case was reported; the town of Vânaturi (Vrancea county) with a case in 2015; the town of Racoasa (Vrancea county) with a case in 2014.

\section{CONCLUSIONS}

Given the huge volume of data available to us today, introducing new approaches to analyzing medical data, in our situation, is absolutely necessary. In recent decades, since the advent of geographic information systems, statistical data have been correlated with spatial component, either as a distribution in a geographic space, or the establishment of the determinant factors present in the geographical environment.

The methodology used in this paper offers a clearer view on the distribution of thyroid cancer on the surface of Romania, helping to draw conclusions. Extreme values are identified in the area of large urban centers, heavily polluted, but also in areas with industrial activity (more or less nowadays). From here we can draw a general conclusion, that the appearance and development of thyroid cancer is influenced by these factors present in the geographic environment, following the study of this subject in future articles. 


\section{REFERENCES}

[1]. Francesca Giusti, Alberto Falchetti, Francesco Franceschelli, Francesca Marini, An-nalisa Tanini, and Maria Luisa Brandi. Thyroid Cancer: Current-Molecular Perspectives, Journal of Oncology, vol. 2010.

[2]. Romain Guignard, The're`se Truong1, Yannick Rougier, Dominique Baron-Dubourdieu, and Pascal Gue'nel1. Alcohol Drinking, Tobacco Smoking, and Anthropometric Characteristics as Risk Factors for Thyroid Cancer: A Countrywide Case-Control Study in New Caledonia. American Journal of Epidemiology vol. 166, No. 10, 2007.

[3]. John P. Hanley, Erin Jackson, Leslie A. Morrissey, Donna M. Rizzo1, Brian L. Sprague, Indra Neil Sarkar, and Frances E. Carr. Geospatial and Temporal Analysis of Thyroid Can-cer Incidence in a Rural Population. Thyroid, vol. 25(7), pp 812-822, 2015.

[4]. Bithell, J., F. A classification of disease mapping methods. Statistics in Medicine, 2000.

[5]. Jarup L, Best N, Toledano M., B, Wakefield J, Elliott P. Geographical epidemiology of prostate cancer in Great Britain. International Journal of Cancer vol. 10, 2002.

[6]. Zhang J, Lawson A., B. Bayesian parametric accelerated failure time spatial model and Pts application to prostate cancer. Journal of Applied Statistics vol. 8 pp 591-603, 2011.

[7]. Onicescu G, Lawson A., B, Zhang J, Gebregziabher M, Wallace K, Eberth J. Bayesian accelerated failure time model for space-time dependency in a geographically augmented survival model. Statistical Methods in Medical Research, vol 26, pp 2244-2256, 2015.

[8]. Maguire , D., J., Goodchild, M., F., Rhind, D., W. Geographical Information Systems: Principles and Applications. London: Longman. SAGE journals, vol. 17, 1993.

[9]. Croner, C., M. Geographic Information Systems (GIS): New Perspectives in Understanding Human Health and Environmental Relationships. Statistics in Medicine, vol. 15, pp 1961-1977, 1996.

[10]. Correa P, Piazuelo M., B, Camargo MC. Etiopathogenesis of gastric cancer. Scandinavian Journal of Surgery, vol. 95, pp 218-24, 2006.

[11]. Crew K., D, Neugut A., I. Epidemiology of gastric cancer. World Journal of Gastroenterology, vol. 12, pp 354-62, 2006.

[12]. Correa P. Clinical Implications of recent developments in gastric cancer pathology and epidemiology. Seminars in Oncology, vol. 12, pp 2-10, 1985.

[13]. Ghetian, C., B., Parrott, R., Valkman, J., E., Lengerich, E, J. Cancer registry policies in the United Station and geographic informations systems applications in comprehensive cancer control. Elsevier, vol. 87, pp. 185-193, 2008.

[14]. Brewer, C., A. Basic Mapping Principles for Visualizing Cancer Data Using Geographic Information Systems (GIS). American Journal of Preventive Medicine, vol. 30, 2006.

[15]. Charles M. Croner, Geographic Information Systems (Gis): New Perspectives in understanding Human Health and Environmental Relationships. Statistics in Medicine, vol. 15, pp 1961-1977, 1996. 